\title{
Strengthening health systems globally: a lingering challenge of funding
}

\section{Vivian Lina, Abdul Ghaffarb,e, Swee Kheng Khor and K Srinath Reddy}

a Public Health, LKS Faculty of Medicine, University of Hong Kong

b Alliance for Health Policy and Systems Research, World Health Organization, Geneva, Switzerland

c United Nations University International Institute for Global Health, Kuala Lumpur, Malaysia

d Public Health Foundation of India, New Delhi, India

e Corresponding author: ghaffara@who.int

\section{Article history}

Publication date: 10 November 2021

Citation: Lin V, Ghaffar A, Khor SK, Reddy KS. Strengthening health systems globally: a lingering challenge of funding. Public Health Res Pract. 2021;31(4):e3142115. https://doi. org/10.17061/phrp3142115
In 1996, a World Health Organization (WHO) Ad Hoc Committee on Health Research recommended health policy and systems research (HPSR) as a global investment priority to strengthen health systems performance. ${ }^{1}$ The Alliance for Health Policy and Systems Research (Alliance) was subsequently established by WHO, development partners and national governments to advocate for greater financing and use of HPSR.

Over the past 25 years, the HPSR community's advocacy efforts have led to an increase in HPSR funding, especially by global health funders and organisations. This has yielded a significant increase in the generation of policy-relevant knowledge for health system strengthening, particularly in lowand middle-income countries (LMICs). ${ }^{2}$ However, most of this funding comes from a small number of international funders, making it vulnerable to changing donor priorities. We need stronger, sustained investment in HPSR - especially at a time when the coronavirus disease 2019 (COVID-19) pandemic has demonstrated the need for stronger health systems and context-relevant knowledge. As described by Stuckler et al. in this special issue of Public Health Research \& Practice, the "political window of opportunity could not open any wider" than right now, to mobilise resources and partners to strengthen our health systems. ${ }^{3}$

Six studies on the state of play of HPSR commissioned by the Alliance, covering all WHO regions, are reported in this special issue. Together, they reveal that funding for HPSR at country level remains a serious and lingering challenge. ${ }^{4-9}$ Identifying funding sources and current national priorities for HPSR are starting points to understand the challenges and possibilities of building national capacity to conduct this type of research, which is vital to strengthening health systems. Researchers for this special issue encountered many issues in identifying the determinants of HPSR funding. Sourcing adequate and appropriate information was the most basic challenge. Even when data did exist, different definitions of HPSR made comparisons difficult. Because HPSR is often a small subset of funded health research, there is typically no specific budgetary allocation for it.

We discern several factors that undermine the value and promise of HPSR. Firstly, governments globally pay greater attention to basic science/ clinical research, compared with HPSR. In the paper covering post-Soviet states, for example, Gotsadze and Zoidze report that most research and 
development funding is allocated to fundamental sciences and biomedical research - fields with more influential long-standing institutional legacies. ${ }^{8}$ A similar focus on biomedical and clinical research is discussed by Becerra-Posada and colleagues in the Latin America

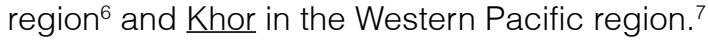

Secondly, there is over-medicalisation of health research, because health research follows the trend for over-medicalisation of healthcare, especially due to 'Big Pharma' and other interested parties emphasising disease-oriented healthcare compared with health promotion and prevention. Thirdly, randomised controlled trials are touted as the gold standard for health research and there is a strong lobby, especially among funders, for everything to be measured through causal models using statistics. Health systems are complex and can't necessarily be measured with the traditional linear logic models. And finally, the evidence-based medicine movement has had undue influence on informing policy choices. Evidence-based medicine is concerned with clearly defined independent interventions that result in well-specified health outcomes, such as vaccine and drug trials. On the other hand, health policy and health system reform are classic 'wicked problems' that deal with dynamic interactions of several complex adaptive systems.

The COVID-19 pandemic has resulted in significantly shortened processes of research translation (bench to bedside, bedside to health system) and demonstrated the importance of improved understanding of health system functioning and policy. Campbell and colleagues report on a world-class example in NSW, Australia, of how an emergency research program in response to COVID-19 resulted in the rapid translation of research into health decision making..$^{10}$ Findings from their project highlight the importance of a well-trained public health research community and a collaborative research sector.

Health systems are embedded in the history, politics, ideologies, economics, cultures, and professional and community networks of any society. These complex problems are difficult to solve through simplistic linear approaches, as they are interconnected by nature and subject to changing contexts and constraints. Health policies and systems decisions rely not only on epidemiological and medical research but require a broader range of information, like perceived health needs, community preferences, provider behaviour, cost implications, distribution of benefits, political interests and imperatives, and other factors. Furthermore, decision making on health policies and systems involves tradeoffs between investments in multiple sectors relevant to health.

However, good-quality research evidence not only informs decision making, but can also provide a way to reconcile stakeholder understanding and interests. The HPSR community must invest time and effort to impact policy making meaningfully and consistently, by building institutional capabilities, trusting relationships and a track record. HPSR leaders and national governments must lay the foundational building blocks of HPSR over time, through sound information systems and longitudinal data sets, a multidisciplinary research workforce and adequate funding.

HPSR also needs multidisciplinary teams to be created. As reported by Mathur and colleagues in their paper focusing on South East Asia, many national funding agencies have siloed funding streams that do not facilitate multidisciplinary collaborations. ${ }^{4}$ Researchers with medical and public health backgrounds need new training curricula that focus on non-health-specific knowledge sets (such as political science, sociology and economics) while those from social sciences will need to learn about the dynamics of health transitions and evidence-based medicine. Both quantitative and qualitative research skills enrich the multidisciplinary teams, along with social competencies (including communication skills, stakeholder engagement and demand generation abilities).

Advancing HPSR in low- and middle-income countries (LMICs) poses a big challenge. Yet, LMICs need this type of research more than ever to efficiently use available resources and improve health system performance - the impacts of the COVID-19 pandemic on health systems worldwide have highlighted the urgent need for this. LMICs must have sound evidence, about how to achieve good health outcomes through making correct choices in health and public policy and investing in efficient forms of service delivery. ${ }^{11}$

Many LMICs already have mechanisms for funding health and medical research, as described by the six research papers in this special edition. Although many countries have long-established medical research institutions, existing practices and systems often reflect either colonial legacy or current influence of external donors. These donors typically support specific timebound development assistance projects, which may help build some capacity for HPSR but are not sustainable investments.

The papers also highlight that it is important for countries to begin collecting granular data on HPSR funding allocations and working to agree on a common understanding of what constitutes HPSR so they can gradually raise its capacity, stature and allocations, and position HPSR as an investment with good returns.

Increasingly, the authors' experiences show that it is important to build research partnerships, which connect producers and users of HPSR from the outset throughout the research process. This helps to direct research to key policy questions. ${ }^{12,13}$ Productive partnerships between funders, producers and users of HPSR will require clear mechanisms, sound processes and effective communications. For such partnerships to work, researchers must understand competing policy priorities, decision-making styles and political constraints. Policy makers must understand the purpose, process and products of research. A mindset change may be 
required, for researchers to become committed to solving real-world problems related to policy and practice and for politicians to consider the best evidence available, separate from ideological or political positions.

Now is the time, as the world comes to terms with COVID-19, for HPSR proponents to seize the opportunities provided by increased political and public attention to health policies and systems. We hope that the contents of this special edition will enhance understanding of the global funding landscape of HPSR and offer ideas for strengthening HPSR capacity across the world.

\section{Acknowledgements}

This special issue of Public Health Research \& Practice was supported by and developed in partnership with the Alliance for Health Policy and Systems Research, World Health Organization. The Alliance is supported through both core funding as well as project-specific designated funds. The full list of Alliance donors is available here: ahpsr.who.int/about-us/funders. However, this work has been supported by a grant from the United States Agency for International Development (GHA-G-00-09-00003 Amendments 42 and 48 ) to the Alliance.

\section{Peer review and provenance}

Internally peer reviewed, invited.

\section{Competing interests}

None declared.

\section{Author contributions}

$\mathrm{VL}$ led the writing of the Editorial, with input and revisions from $A G, S K K$ and KSR.

\section{References}

1. Ad Hoc Committee on Health Research Relating to Future Intervention Options. Investing in health research and development: report of the Ad Hoc Committee on Health Research Relating to Future Intervention Options. Geneva: World Health Organization; 1996 [cited 2021 Oct 11]. Available from: apps.who.int/iris/ bitstream/handle/10665/63024/TDR_Gen_96.1_pp1-34. pdf?sequence $=1$ \&isAllowed $=y$
2. The Alliance for Health Policy and Systems Research. World report on health policy and systems research. Geneva: WHO; 2017 [cited 2021 Oct 11]. Available from: apps.who.int/iris/bitstream/hand le/10665/255051/9789241512268-eng.pdf?sequence=1

3. Stuckler D, McKee M, Kentikelenis A. Are we making the same mistakes? We need to invest in HPSR now more than ever. Public Health Res Prac. 2021;31(4):e3142116.

4. Mathur MR, Gurung A, Selvaraj S, Reddy KS. Health policy and systems research: an inconsistent priority in South East Asia. Public Health Res Pract. 2021;31(4):e3142118

5. El Rabbat M, El-Jardali F, Fadlallah R, Soror S, Ahmadnezhad E, Elsheikh B, Dabis J. Funding for health policy and systems research in the Eastern Mediterranean region: amount, source and key determinants. Public Health Res Pract. 2021;31(4):e3142119.

6. Becerra-Posada F, dos Santos Boeira L, García-Godoy B, Lloyd E, Martínez-Sánchez HX, O’Donnell C, et al. Politics and political determinants on health policy and systems research funding in Latin America and the Caribbean. Public Health Res Pract. 2021;31(4):e3142120.

7. Khor SK. Key themes and opportunities for health policy and systems research funding in the Western Pacific region. Public Health Res Pract. 2021;31(4):e3142123.

8. Gotsadze G, Zoidze A. Soviet legacy is still pervasive in health policy and systems research in the post-Soviet states. Public Health Res Pract. 2021;31(4):e3142121.

9. Uneke CJ, Okedo-Alex IN, Johnson EA, Akamike IC, Chukwu OE, Eze II, Uneke BI. An assessment of perceived prioritisation, and resource allocation for health policy and systems research in West Africa. Public Health Res Pract. 2021;31(4):e3142122.

10. Campbell D, Edwards B, Milat A, Thackway S, Whittaker E, Goudswaard L, et al. NSW Health COVID-19 Emergency Response Priority Research program: a case study of rapid translation of research into health decision making. Public Health Res Pract. 2021;31(4):e3142124.

11. Gilson L, Marchal B, Ayepong I, Barasa E, Dossou JP, George A, et al. What role can health policy and systems research play in supporting responses to COVID-19 that strengthen socially just health systems? Health Policy Plan. 2020;35(9):1231-6.

12. Marten R, El-Jardali F, Hafeez A, Hanefeld J, Leung G M, Ghaffar A. Co-producing the covid-19 response in Germany, Hong Kong, Lebanon, and Pakistan. BMJ. 2021;372:n243

13. Gilson L, Barasa E, Brady L, Kagwanja N, Nxumalo N, Nzinga J, et al. Collective sensemaking for action: researchers and decision makers working collaboratively to strengthen health systems. BMJ. 2021;372:m4650.

\section{Copyright: (c) (i)}

(c) 2021 Lin et al. This article is licensed under the Creative Commons Attribution-ShareAlike 3.0 International Licence, which allows others to redistribute, adapt and share this work for any purpose provided they attribute the work and indicate if changes were made. See: https:// creativecommons.org/licenses/by/3.0/igo/ 